\title{
OPPORTUNITIES AND CHALLENGES OF TOURISM INDUSTRY IN THE CONTEXT OF VISIT NEPAL 2020
}

\author{
Bharat Prasad Badal', Suman Kharel ${ }^{2}$
}

\begin{abstract}
Welcoming two million tourists in 2020, is itself a challenge and the challenge from another side is a great opportunity for Nepalese tourism development. Only tourism can transform the nation because other sector of economy requires extensive capital and skillful human resource. Nepal cannot compete with India in Agricultural Production and with China in other industrial productions. Nation's investment in Agriculture and Industries are in high risks. At this crucial juncture of time Nepal government has announced visit Nepal 2020, which could be a milestone of Nepalese Economic Development. To analyze the challenges and opportunities to welcome 2 million tourists in 2020 the study has been designed. Tourism is a social phenomenon that promotes the movement of visitors to a region or destination in the world with certain natural or artificial features aimed to leisure and rest. Methodologically, it is a qualitative descriptive analysis of available secondary information on Nepalese tourism industry and academia. The method analyzes entire facts qualitatively and interprets the meaning of tourism information.
\end{abstract}

The tourism industry's viability is based on its natural and cultural environment. The environment encompasses air, land, water, art, history, architect, festivals, and hospitability of people. The foreign tourists and excursionists' primary interest in Nepal is to study its culture and nature not dust, dirt, and mismanagement of roads etc. Mayors of local governments must be aware on these issues. Nepal's unique form of musical expression and cultural vibes are becoming lost resulting in cultural dilution. Accessibilities

1 Dr. Badal is a Visiting Faculty, Central Department of Rural Development, Kathmandu, TU.

2 Mr. Kharel is a Lecturer, Central Department of Rural Development, Kathmandu, TU. 
and identification of tourist circuit along with standard food and well accommodation facilities are prior for tourism development for visit Nepal 2020.

Keywords: Industries, Nepalese Tourism, Opportunities and Challenges

\section{INTRODUCTION}

Nepal Visit Year 2020 is approaching close. The preparation to welcome the 2 million tourists, entire state is mobilized. Every stakeholders of Nepalese tourism industry is working day and night to make the mega event success. Whereas tourism is a social phenomenon that promotes the movement of visitors to a region or destination in the world with certain natural or artificial features aimed to leisure and rest (Fonseca 2012). In Nepal as well the tourism industry is complex and hyper-dynamic, comprised of a highly fragmented value chain. Tourism, in the economic context of the 21 st century, is an essential activity in the structure of the economic mechanism and has an active role in the development and modernization of the economy and society. The United Nations World Tourism Organization (UNWTO 2015) forecasted that international tourism, from 2010 to 2015, would have an increase of $4 \%$ every year. Increasing rate of tourists' arrival is a good symbol of the target and achievements of visit Nepal 2020. After the success of Visit Nepal Year 1998 and Nepal Tourism Year 2011, the Tourism Board of Nepal introduced Visit Nepal Campaign 2020. The Campaign was announced in 2015 to be held in 2018 but was later postponed to 2020 due to the devastating earthquake.

Tourism is the temporary movement of people to destinations outside their normal places of work and residence, the activities undertaken during their stay in those destinations, and the facilities created to cater to their needs. The movement of persons can be further clarified by categorizing them into "excursionists" and "foreign tourists" (Bhola-Paul 2015). The United Nations Conference on Travel and Tourism in Rome in 1963 describes tourist as persons staying for at least 24 hours in the country visited and the excursionist staying for less than 24 hours in the country visited (Bhola-Paul 2015). Whoever visits a new place more than 24 hours will be a tourist and the host must welcome those guests as God in Nepal Atithi Devo Bhawa.

Tourism, in the economic context of the 21 st century, is an essential activity in the structure of the economic mechanism and has an active 
role in the development and modernization of the economy and society. Therefore, Nepal has to work out a lot to achieve the tourism target. For the visitors, Nepal is a paradise from 10 world famous tourism destinations in Nepal. One of the reasons to visit Nepal is for trekking and climbing mountains. Nepal boasts pristine natural beauty, sky-high Himalayas Range and endless culture and traditions spread out all over the country. There are countless ethnic groups each following their distinct art and religions. These diverse traditions and lifestyles are prominent features of Nepalese people. Nepal is a perfect combination of nature and culture.

Tourism year 2020 encompasses travel organizers, accommodation providers, tourist offices, visitor attractions, transport activities, and a litany of other support systems and direct and tertiary mechanisms for each of them. Sustainable initiatives across this chain moreover are becoming increasingly important, while competition intensifies, and consumertourists - now digitally connected and savvy - also are more demanding (Shultz et al. 2015). These realities potentially help and hinder a country's tourism industry, and the broader marketing system that both enables and benefits from it. Conventional wisdom commonly holds tourism and its related activities positively impact social and economic well-being (Shultz et al. 2015). Tourists are the sources of private and public income. Generally, government collects income from tourists Tax, levy royalty Visa etc. Private sectors generate revenue providing different facilities to tourists like lodging, fooding, trekking, rafting, boating, travelling etc. By attracting more tourists and increasing their average stay in Nepal, public and private income can be increased. Local governments must take an initiative toward the development of tourism infrastructure and facilities.

Tourism, in global perspective, is a collection of activities, services and industries that delivers a travel experience. Include transportation, accommodation, eating and drinking establishment. Retail shops entertainment business, activities facilities and other hospitality services provided for individuals or groups, travelling away from home. The world tourism organization (WTO) claims that tourism is currently the world's largest industry with annual revenue of over $\$ 3$ million dollars.

Tourism has, by virtue of its activity, implications in the social, political, cultural and economic areas of activities. The sheer volume and complexity of the offer of tourist services have led to the development of travel and tourism industries. Because of this, the phenomenon of tourism 
should be regarded as a separate branch of economy. This branch of the economy is closely linked with the development levels and growth of the other branches of the economy (Bunghez 2016). Nepalese scholars and policy makers must be insightful on planning and development. It is necessary to complete the renovations before 2020. Kathmandu alone, there are 7 UNESCO World Heritage sites including Pashupatinath, Boudhanath and Durbar Squares

\section{OBJECTIVES}

The general as well as specific objective of the study is to identify the opportunities and challenges of Nepalese tourism Industry. Tourism is smokeless industry although it has various pros and cons. Thus the main objective is to identify its opportunities, strengths and benefits. On the other hand, it is not free from criticisms, challenges and disadvantages. The study has analyzed the opportunities and challenges in Nepalese Tourism Industry focusing on Visit Nepal 2020.

\section{METHODOLOGY}

The information for this article was compiled and summarized through the review of literature, program documents, web pages, brochures, and maps. Personal communication with program officers active in tourism development and several individuals from the private sector was also an important means of gathering and validating data. It is a qualitative descriptive analysis of available secondary information on Nepalese tourism industry. The method analyzes entire facts qualitatively, interprets the meaning and many more. It is a common method to evaluate the literature on the selected issue like tourism. It is normally a literature review.

\section{DISCUSSIONS}

Visit year celebration is a program designed to boost the tourism industry, was started from 1998 in Nepal. Many tourist products and services are based only on the aforementioned existing natural or cultural/historic promise, most of which do not have acceptable marketing support in forms of infrastructure, amenities, and digital communication to optimize the tourist experience, and to alert potential and actual tourists of the existence and nuances of those experiences (Shultz et al. 2015). An obstacle is the lack of understanding or appreciation for the role that destination-management organizations must play at all levels and throughout the marketing-system required for a thriving tourism sector. Current policies and practices reveal ineffectual and inefficient - and often uncompetitive - management across 
the marketing mix for touristic goods and services throughout the country. Thus local governments have to take initiatives. Nepal has 852 species of birds and bird watching has evolved into a sought out activity of tourists. Nepal also homes several endangered species such as the Bengal Tiger, One Horned Rhinoceros, Bengal Fox, Red Panda and the elusive Snow Leopard.

Proper holistic planning and implementation of actions; development of new attractions, products and services; local public private partnerships; investments in basic infrastructure and tourismspecific infrastructure; identifying and developing target markets; market intelligence; quality management; easier access to finance for tourism establishments; hospitality and services-related education and so on, all are vital to the well-being of tourist-consumers, the tourism industry (Shultz et al. 2015)

Environmentally, tourism has provided protection to the natural environment through financial contribution from entrance fees and the maintenance and enhancement from government funding. The financial contribution from tourism has provided for the management and expansion of protected areas (Bhola-Paul 2015). Tourism is a significant export product for nation and contributes economically to the island through its GDP, the employment it provides, and the number of cruise calls made by the excursionists and the foreign tourist stop-over arrivals.

Some of the role or importance of the Tourism industry to Economic Development in Nepal are following points: Source of Foreign Exchange Earning, Exchange of Art and culture, Increase in Employment opportunities, Increase in Government Revenue, Development of cottage and small scale industries, Development of infrastructure, Increase in Social facilities, Conservation of Natural Resources and Human Resource Development.

The history of tourism starts in Nepal from the expedition of George Mallory and Andrew Sandy Irvine who were disappeared in 1924 in an attempt to conquer Everest. However, it was in 1953 Edmund Hillary and Tenzing Norgay Sherpa first conquered Mt. Everest (8848m). Annapurna I was the first 8000 meter peak to be climbed. Maurice Herzog and Louis Lachenal reached the summit on 3 June 1950.

\section{Opportunities}

By 2020, the government plan to operate two new International Airport, Pokhara, and Lumbini and introduce new Airbus 330-200 to provide airline services to a large number of tourists. The government also plans to run Tribhuwan International Airport for additional hours from 
regular hours to ensure availability of services to incoming and departing tourists. The private hotel sector has planned to add 4000 new rooms in four and five-star category in Kathmandu, Chitwan, and Pokhara. Many new international chain hotels, Hilton, Doubletree, Marriott, are expected to operate in 2020 .

In recent years, tourism has boomed into an eye-catching industry across the world because of the significant role it plays in stimulating consumption, promoting trade, and enhancing international communication. Many countries in Asia, Latin America, and Sub-Saharan Africa place a huge weight on the economic effects of tourism. So Nepal has to take the benefits from the development. It is obvious that it has taken the step called Visit Nepal 2020.

It has tremendous and quite unique tourism potential in Nepal. This could be tapped mainly through the concept of eco-tourism, nature based wildlife tourism, adventure tourism, culture based heritage tourism, leisure tourism, and international border tourism. These could be some special tourist packages for 2020. Many incentives and financial assistance are being proposed for creation of tourist infrastructure through private participation (Deka et al. 2012). Nepal is renowned for its natural beauty, high Himalayan and culture. These qualities are much sought after traits in tourism industries but need to be protected as the industry develops. Supporting the culture and environment, there are a diverse range of products available to people travelling, from adventure tour and mountaineering options to relaxing honeymoon packages and these products are well dispersed. To realize tourism's great potential to contribute to poverty reduction and sustainable development, it must be sensitively planned and deliberately linked with the development needs of mountain people and the challenges of their mountain environment. Failure to do so may result in an accumulation of benefits to the (mostly urban) rich - in the case of Nepal, for instance, Kathmandu based tour operators rather than mountain communities per se - and might actually increase the economic, environmental, and socio-cultural problems of the visited areas (Kruk et al. 2011)

People need to be motivated to travel to the state for relaxation on the compassion of the nature, to see 8 highest mountains in the world, National Parks, cultural cities, flora and fauna. Nepal is rich in natural beauty and culture and although they should capitalize on what they already have, they should strive to work on areas. The heritage place like Kathmandu, Bhaktapur and Lalitpur must be ornamented and with proper publicity about its fact should be incorporate with the national tourism. Education could become an area of priority for development. Inclusion of 
vocational/regular course on tourism, hospitality and management which will create job opportunities for the youth and it will act as pull factor to develop Nepalese tourism development. Arrangement of package tour is now famous in worldwide. Government must have to consider this with adequate planning and also need to examine the recommendation of 20 years' perspective plan for the sustainable development of tourism in local governments as well. But focus must be on Visit Nepal 2020 at this point of time.

Nepal commands immense possibilities of Economic Development through tourism industry. The basic requirement for its development is geographical attractions. Switzerland in Europe and Kashmir in south Asia are highly developed in the sphere of Tourism industry. Nepal's geographic environments are almost identical to those existing in Kashmirs and Switzerland. So from the comparative point of view, Nepal also possesses the same possibilities of Economic Developing through tourism industry. In addition to Natural beauties, Nepal has also host of cultural and religious implications for attracting tourists. The fundamental bases for developing this industry in Nepal are as outlined below: Natural Beauty, Climate Variety, Store House of Antique Arts, Cultural Heritage, Wildlife, Rural settlement, Less Expensive, and Birth place of Buddha, Bhrikuti, and Janaki.

Publication of tourist information, construction of tourist map, travel guide book publications etc. are in need of attention for fruitful development of municipal tourism. Government level appeal for some special discounted package for leisure travelers, Concession package for incoming excursion groups, weekly or biweekly arrangement of deluxe tourist bus services are basic need of tourism development. Himalayan tourism, Heritage tourism, wildlife tourism, rural tourism and adventure tourism are the main thrust of for the state. Hence Government and Tourism Department need to make optimum use of all these available facilities wisely and efficiently for Visit Nepal 2020.

Sustainable tourism is in its purest form, an industry which attempts to make a low impact on the environment and local culture, while helping to generate income, employment, and the conservation of local eco-systems. It is responsible tourism which is both ecologically and culturally sensitive. Sustainable tourism must incorporate as part of its mandate low impact on the environment and local culture (Bhola-Paul 2015). Therefor Visit Nepal 2020 will be only one milestone for the transformation of the country. The specific opportunities are: 
- Visiting Lumbini is not only the pilgrimage of birth place of lord Buddha, it is the symbol of peace, love and humanity around the world. Nepal is the country of peace and of course birth place of Buddha.

- Once in life a Hindu must visit Pashupatinatha.

- To triumph the world one need to be in the top of the world - Mt. Everest. If one is not in the top, is not in the top. Nepal is the country to conquer the earth. Among 10 top high mountains 8s are in Nepal. (Mt. Everest, Mt. Kanchanjangha, Mt. Lhotse, Mt. Makalu, Mt. Choyu, Mt. Dhawalagiri, Mt. Manasulu, Mt. Annapurna all are 8000 meter above)

- To visit world heritage site one must visit Nepal. Nepal has 10 UNESCO identified heritage sites and seven are within Kathmandu valley (Pashupatinatha, Swyambhunath, Baudhanath, Hanumandhoka, Patan Durbar Square, Bhaktapur Durbar Square, Changunarayan, Chitwan National Park, Sagarmatha National Park and Lumbini)

- Nepal is Trekker's paradise: walking through the wild ways watching birds and stunning snowcapped mountains is like walking in heaven.

- Riverside Recreations in Nepal is awesome: Nepal has 6000 rivers for rafting, kayaking, conuing, bungee and many more.

- Kathmandu is the city of temple: one can see in any nook and corner a temple in Kathmandu

- Cows and Dogs are God in Nepal: A Unique Culture in the world

- Bird and Butterfly Watching, Jungle walk, and wild life are quite interesting in Nepal

- A canvas of prayers' flag - Nepal.

From next point of view opportunities can be categorized as:

Neighbouring markets: With the burgeoning middle class in India and China, tapping more effectively into these markets represents a considerable opportunity. These are very different from Nepal's traditional tourist visitors, and may hence need careful supplementing of existing product offerings or the development of new products (Jones 2013).

Domestic tourism: Little is known about domestic tourism in Nepal but, given that its value is estimated to be at least equal to international tourism, it is poorly understood and under emphasized by government, international agencies and some in business.

Pilgrimage: Religious tourism is a growth market, and there is a wealth of cultural and religious sites suitable for development as pilgrimage 
products. These assets currently remain underdeveloped and it is likely that very little money is captured from tourists visiting for these purposes. In particular, there is a dearth of higher-value offerings.

High-value products: There is space for the development of highvalue tourism products. For example, a number of areas are suitable for development as mountaineering destinations, and high-value services can be established around existing products.

Supplementing trekking products: There is a gap in the market for shorter treks (popular especially with older visitors) and treks in the rain shadow during monsoon (out of peak season), and areas near the centre of the country are suitable for development as high volume trekking routes.

Nature tourism: There is also considerable potential to develop nature tourism - despite the fact that $23 \%$ of the land area is covered by national parks and PAs, the vast majority of visitors are currently focused on a small number of these areas (Jones 2013).

Business and events tourism could be developed in a number of areas, building on the steady flows currently witnessed. Pokhara would be an ideal destination, if international and national connectivity could be improved. Increasing numbers with decreasing value capture, along with signs of key assets reaching carrying capacity and degrading, represent the central problem for the Nepali tourism industry (Jones 2013).

\section{Challenges}

Visit Nepal 2020 has many challenges as well. Budget is not very promising for the tourism development. The challenge for sustainable development through nature tourism is how to design a public policy directed towards the competitiveness of this sector at its national and international level, which results in improved economic and social wellbeing for the communities where corporations operate. In terms of concrete actions in the case of private companies, it must maximize their social responsibility, while creating support and encouragement to maintain and improve the quality of their operation. In addition, both communities and private companies should generate actions to comply with the standards established in this area, and also seek to obtain certification of service quality, both domestically and internationally (Fonseca 2012). The mass arrival of tourists in cities represents a substantial percentage of the total volume of tourists in tourism countries and a notable contribution to the creation of wealth. Wealth comes with wraths as well. It has like such many challenges. Many of the underlying weaknesses that constrain the operation 
and development of tourism in Nepal are symptomatic of broad, systemic problems, including:

Poor infrastructure, including poor coverage and low quality of roads, and unreliable domestic air services, increases the costs and reduces the value captured from tourists. Poor availability of services such as electricity and sanitation means it is costly to provide adequate facilities and levels of services, especially in more remote parts of the country (Jones 2013). Human resource constraints, such as low levels of education and literacy, and deficiencies in vocational education and skills training reduce private sector capacity. This presents challenges to businesses looking to provide higher-quality services, and also constrains poorer people from benefiting from tourist flows in both rural and urban areas.

Economic governance issues affect the sector, such as poor implementation of public investment, macroeconomic problems with respect to balance of payments, poor monitoring and enforcement of regulations around business standards and practices and rent-seeking and corruption by political parties and others. A poor investment environment stems predominantly from political and administrative instability, a lack of consistent planning and implementation, insufficient government support arrangements and escalating labor disputes. A lack of leadership in the sector further constrains its development, with few decisive actions taken to articulate a vision, to signal intentions to domestic and international investors or to priorities between the many activities and destinations (Jones 2013). While the relieving of the issues above would be sufficient to enable the healthy development of the sector, it is not necessary that they be addressed at scale in order to do so. With respect to political instability, for example, tourism businesses are often exempted from strike action, with tourist vehicles allowed to ply the roads even when a full shutdown is in force (Jones 2013).

Though, Nepal has huge potentialities regarding tourism, it has not contributed as it can because of the following reasons or challenges: Lack of transport and communication, lack of recreational facilities, lack of trained manpower, problem of pollution, lack of advertisement, inadequate tourist centers, lack of quality hotels, and lack of security. These are the major hurdles of the campaign of Visit Nepal 2020.

There are serious problems for nearly every one of the country's established destinations, such as: in Pokhara there are issues of ad hoc and haphazard land use development, which is damaging the image of key areas. Phewa Tal, the lake that is the signature attraction of the city, faces problems with pollution, waste and siltation, which have led to dangerously 
low water quality and may mean there is no lake remaining in 40 years' time (the current area is already less than half of its original size) (Jones 2013).

In Lumbini the numbers of visitors are thought to top 800,000 with very little revenue collected, and there are reports of degradation of key attractions, with only one of seven pillars that mark the key pilgrimage sites still standing. In Chitwan National Park there has been a decline in some key species and their natural habitat, as well as the expulsion from the park of a business that pays more than $70 \%$ of the taxes collected for the district not to mention services provided in-kind towards the upkeep of the park (Jones 2013)what the researchers have faced in Chitwan. In Kathmandu poorly managed and unplanned urban development and poor waste management contribute to an unattractive environment for tourists, while some key cultural sites are degraded. Recently, there has been conflict over the preservation of houses in key world heritage sites which threatens their sustainability (Jones 2013). The local level staff must be trained.

On Mount Everest overcrowding results in queues for the summit that are hundreds of people long, which is causing serious safety hazards and contributed to some of the recent deaths on the mountain. The gateway to Everest, Lukla, has big challenges with waste management and insufficient water services, and annual flight problems see thousands of tourists stranded for days with diminishing supplies and overcrowded conditions (Jones 2013). This is the the big problem that the government has to solve as soon as possible.

In Upper Mustang the promised $60 \%$ of revenues to be recycled to the local area does not arrive, and with the government specified limit of 2,000 visitors per year not enforced. It is forecast that the destination will be undermined within short order owing to unmanaged tourist flows and associated development (Jones 2013).

These trends reduce value capture and inclusion and in the medium term threaten the viability of the sector as a whole. The actual and potential consequences of these trends are hard to quantify, but likely to be quite large. The destinations facing problems with degradation mark out the most popular attractions for foreign tourists and see the vast majority of tourists between them - so losing them would be a serious blow to the sector (Jones 2013).

The global tourism industry has grown about 50\% in the past decade, despite setbacks caused by terrorism, pandemics and times of political and economic unrest (Deka et al. 2012). Global tourism was affected by several worldwide disasters starting in 2008 and reaching full 
impact in 2009. The economic recession hit first world countries hard, which had global implications. Swine Flu, Birds Flu etc. are example for which the developed countries faced a major setback in the economic sector. Hence in last decade tourism faced a negative growth compared to the previous decade. But as per the World Tourism report tourism industry has bounced back again in the year 2010. It has a direct economic impact in the developing countries like in India and China for Nepalese development. Accessibilities and identification of tourist circuit along with standard food and well accommodation facilities are prior for tourism development.

\section{CONCLUSIONS}

The tourism industry's viability is based on its natural environment. The environment encompasses air, land, and water. The foreign tourists and excursionists' primary interest in Nepal is to study its glorious culture and fascinating nature not dirt, dust and mismanagement. So, the Mayors of local government must be aware of developing tourist friendly infrastructures and amenities. The unique form of musical expression and cultural vibes are becoming lost resulting in cultural dilution. The commercialization of Nepalese festivals offered to the foreign tourists and excursionists can be seen more fruitful. The influence of tourism on the environment has led to research on the development of sustainable tourism. Scholars from popular destinations and their governments are actively conducting sustainable tourism research, and their contributions to the field have achieved global recognition. Accessibilities and identification of tourist circuit along with standard food items and well accommodation facilities are prior for tourism development for Visit Nepal 2020.

\section{REFERENCES}

Bajracharya, R. (2018). Tourism education and Nepal mountain academy: A critical debate. Voice of Himalaya 1: 15-20 Nepal Mountaineering Association.

Bhattarai, K.D. (2018). The China-India-Nepal triangle: Will India agree to cooperate with China in Nepal's development? Kathmandu: The Diplomat.

Bhola-Paul, H.M. (2015). Tourism challenges and the opportunities for sustainability. Journal of Tourism and Hospitality Management, 3(9-10): 204-213. doi: 10.17265/2328-2169/2015.10.004.

Budhathoki, A. (2019). China and India are fighting over Nepal's railways. Kathmandu: Foreign Policy. 
Bunghez, C.L. (2016). The importance of tourism to a destination's economy. Journal of Eastern Europe Research in Business \& Economics 1(9) Article ID 143495, doi: 10.5171/2016.143495.

Chhetri, T.B. (2018). Federal democratic republic Nepal: Deepening problems and prospects. Journal of Political Science 18: 114-142.

Dahal, B.K. (2018). Nepal, India and China: Fostering ties that bind. Kathmandu: The Kathmandu Post.

Dahal, G. (2018). Foreign relation of Nepal with China and India. Journal of Political Science 18: 46-61.

Deka, G., Pachuau, R. \& Lalmalsawmzauva, K. (2012). Challenges and opportunities for Indian tourism: An analysis of Mizoram. Mizoram University, Aizawl, Mizoram, India, pp. 1-15.

Fonseca, F.G. (2012). Challenges and opportunities in the world of tourism from the point of view of ecotourism. Higher Learning Research Communications, December, pp. 5-22.

Jha, H. B. (2013). Nepal's border relations with India and China. Eurasia Border Review 12: 63-75.

Jones, H. (2013). Entry points for developing tourism in Nepal what can be done to address constraints to inclusive growth? United Kingdom: Overseas Development Institute.

KC., K. \& Bhattarai, G. (2018). Nepal's search for prosperity through transit diplomacy. Journal of International Affairs, 2(1): 75-96.

Kruk, E., Kreutzmann, H. \& Richter, J. (2011). Integrated tourism concepts to contribute to sustainable mountain development in Nepal. Kathmandu: GTZ, ICIMOD and BMZ.

Magar, A.A. (2018). Rs 17 billion new investment in tourism in 2017. Kathmandu: My Republica.

Mahato, G. \& Khanal, A. (2018). Politics, economics and leadership in tourism: An analysis for Vision 2020 and 2030. Voice of Himalaya. Nepal Mounteneering Association, pp. 21-33.

MOCTCA. (2019). Nepal tourism statistics 2018. Kathmandu: Ministry of Culture, Tourism and Civil Aviation.

MOF. (2018). Economic survey of Nepal 2017/018. Kathmandu: Ministry of Finance.

MOTCA. (2009). Tourism vision 2020. Kathmandu: Ministry of Tourism and Civil Aviation.

NPC. (2019). Statistical pocket book Nepal, 2018. Kathmandu: Central Bureau of Statistics, National Planning Commission. 
Pokharel, R., Poudel, J., Sharma, A. R. \& Grala, R. K. (2017). A study of climate variability and socioeconomic impact on tourism industry of Nepal. Sustainability in Environment 2(1): 20-34.

Shrestha, D. \& Jeong, S. R. (2016). An ICT framework for tourism industry of Nepal: Prospect and challenges. Journal of Internet Computing and Services(JICS) 17(6): 113-122.

Shultz, C.J., Pestek, A. \& Geroulis, E. (2015). Challenges and opportunities for development of sustainable tourism in Bosnia and Herzegovina. Chicago: Loyola University.

Teker, S. \& Teker, D. (2012). Tourism projects financing: A public-privatepartnership model. Business Management Dynamics 2(5): 05-11.

Thapa, L. (2018). VNY 2020: Opportunities and challenges. The Rising Nepal. Kathmandu.

WTO. (2015). Affiliate members' global reports, volume eleven -publicprivate partnerships: Tourism development. Madrid: World Tourism Organization.

WTTC. (2019). Travel and tourism economic impact 2019 World. Oxford UK: World Travel and Tourism Council. 